\title{
A relação entre intensificação no uso de agrotóxicos e intoxicações nos estabelecimentos agropecuários do Brasil
}

\author{
The relationship between intensification in the use of pesticides and \\ intoxications in Brazil's agricultural establishments \\ Loredany Consule Crespo Rodrigues ${ }^{1}$ (D) José Gustavo Féres² (B) \\ ${ }^{1}$ Programa de Pós-graduação em Economia Aplicada, Universidade Federal de Viçosa (UFV), Viçosa (MG), Brasil. \\ E-mail: loredanyufv@hotmail.com \\ 2Instituto de Pesquisa Econômica Aplicada (IPEA), Rio de Janeiro (RJ), Brasil. E-mail: jose.feres@ipea.gov.br
}

\begin{abstract}
Como citar: Rodrigues, L. C. C., \& Féres, J. G. (2022). A relação entre intensificação no uso de agrotóxicos e intoxicações nos estabelecimentos agropecuários do Brasil. Revista de Economia e Sociologia Rural, 60(spe), e244491. https://doi. org/10.1590/1806-9479.2021.244491
\end{abstract}

Resumo: Este estudo verifica a relação entre a intensidade do uso de agrotóxicos e o número de intoxicações nos estabelecimentos agropecuários do Brasil. A partir dos dados do Censo Agropecuário 2006, utilizou-se do Propensity Score Generalizado (PSG) para tornar os municípios com diferentes intensidades do uso de agrotóxicos comparáveis. Os resultados revelam que a proporção de estabelecimentos com pessoas intoxicadas aumenta à medida que se intensifica o uso de pesticidas, demonstrando efeito negativo e estatisticamente significativo dos agrotóxicos sobre a saúde. Nesse contexto, os serviços de assistência técnica e extensão rural (ATER), por meio do auxílio aos agricultores em relação ao uso e manuseio adequados de pesticidas e do incentivo à adoção de alternativas sustentáveis de manejo de pragas, tornamse essenciais para mitigação dos riscos à saúde associados ao uso de agrotóxicos. Em conjunto com a ampliação dos serviços de ATER, destaca-se a importância do desenvolvimento de produtos mais eficientes e menos nocivos à saúde e ao meio ambiente.

Palavras-chave: agrotóxicos, saúde, estabelecimentos agropecuários.

Abstract: This study verifies the relationship between the intensity of the use of pesticides and the number of intoxications in agricultural establishments in Brazil. Based on data from the 2006 Agricultural Census, the Generalized Propensity Score (GPS) was used to make municipalities with different intensities in the use of pesticides comparable. The results show that the proportion of establishments with intoxicated people increases as the use of pesticides intensifies, showing a negative and statistically significant effect of pesticides on health. In this context, ATER services, by helping farmers concerning the proper use and handling of pesticides and the adoption of sustainable alternatives for pest management, become essential to mitigate the health risks associated with the use of pesticides. Along with the expansion of ATER services, the importance of developing more efficient products that are less harmful to health and the environment is highlighted.

Keywords: pesticides, health, agricultural establishments.

\section{Introdução}

Em 2008, o Brasil se tornou o maior consumidor mundial de agrotóxicos (Carneiro et al., 2015). Embora sua utilização seja uma das formas de aumentar a produtividade agrícola por meio do controle das pragas que causam perdas significativas na produção (Sheahan et al., 2017; Oerke \& Dehne, 2004; Jallow et al., 2017), há diversas externalidades negativas associadas ao seu uso excessivo e inadequado, como os danos à saúde (Kim et al., 2017; Sankoh et al., 2016; Pignati et al., 2014, 2017).

Os efeitos dos agrotóxicos sobre a saúde podem ser crônicos, como alteração do funcionamento do fígado, malformação congênita, problemas respiratórios e de fertilidade (Hu et al., 2015; 
Pignati et al., 2017; Oliveira et al., 2014; Ueker et al., 2016; Regidor et al., 2004; Neghab et al., 2014; Hoppin et al., 2010), ou agudos, como irritação na pele e nos olhos, dor de cabeça, náusea e dificuldade de respirar (Pignati et al., 2017; Soares \& Porto, 2009; Atreya, 2008; Mancini et al., 2005; García-García et al., 2016; Sankoh et al., 2016).

Ressalta-se que, no Brasil, entre 2007 e 2017, mais de 40 mil pessoas foram intoxicadas por agrotóxicos, das quais 1.872 vieram a óbito (Brasil, 2020).

Mesmo diante desse cenário, o ritmo de liberação de agrotóxicos no Brasil tem aumentado significativamente. Entre 2005 e 2019, 3.151 novos agroquímicos foram registrados no país, sendo que a maioria desses registros foi concedida a partir de 2016. Esse fato se torna ainda mais relevante ao observar que apenas 20\% do total de produtos formulados em 2019 são de baixa toxicidade (Brasil, 2019).

É possível que essas liberações aumentem o consumo de pesticidas, elevando a exposição da população a esses compostos químicos. Isso porque, segundo Valadares et al. (2020), o resultado da expansão desses registros tende a reduzir os preços dos pesticidas e, por conseguinte, aumentar seu consumo. Consequentemente, os danos à saúde são potencializados, visto que a maior intensidade do uso de agrotóxicos aumenta a probabilidade de intoxicações (Soares \& Porto, 2009).

De acordo com Hu et al. (2015), a exposição prolongada aos agrotóxicos prejudica o sistema nervoso periférico, as células sanguíneas e o fígado. Sankoh et al. (2016) relatam maiores casos de problemas de pele, náusea, convulsão, distúrbios respiratórios, visão turva, perda de apetite, lacrimação e distúrbio nervoso em agricultores que usam agrotóxicos em relação aos que não usam.

No Brasil, Pignati et al. (2017) identificaram correlação positiva entre os agravos à saúde, mais especificamente intoxicações agudas, incidência de malformação fetal e mortalidade por câncer infantojuvenil, e o uso de agrotóxicos. Ueker et al. (2016) encontraram que a exposição dos pais a pesticidas está associada à malformação congênita. O estudo realizado por Oliveira et al. (2014) sugere que o risco de malformação fetal é maior nas populações intensamente expostas aos agrotóxicos.

Vale ressaltar que, conforme Soares \& Porto (2012), as externalidades negativas provenientes do uso de agrotóxicos não são internalizadas pelos agricultores e fabricantes, favorecendo seu consumo e onerando os sistemas de saúde e da previdência social, por exemplo. Os autores revelam que os custos associados à intoxicação aguda por agrotóxicos para cada dólar gasto na aquisição desses insumos podem variar de US\$ 0,30 a US\$1,281.

Diante do exposto, verifica-se que o uso de pesticidas se torna um problema de saúde pública, sendo necessário haver pesquisas que verifiquem tais impactos e busquem conscientizar a população e auxiliar os policy makers. Adicionalmente, identificar fatores que afetam a saúde da população é fundamental para o crescimento e o desenvolvimento de um país, haja vista a influência da saúde na produtividade do trabalhador e na formação de capital humano, podendo trazer impactos ainda mais significativos a longo prazo. Tal análise se torna ainda mais relevante diante do aumento da liberação de agrotóxicos no Brasil. Vale ainda ressaltar que toda a sociedade está exposta aos pesticidas por meio dos resíduos encontrados nos alimentos (Carneiro et al., 2015). No entanto, segundo Mello \& Silva (2013), residir na zona rural aumenta as chances de intoxicação. De acordo com os autores, o tempo de permanência no local e a dispersão da substância aplicada possivelmente aumentam a exposição dos moradores dessas áreas.

\footnotetext{
${ }^{1}$ A análise foi realizada considerando 176.179 estabelecimentos rurais produtores de milho no estado do Paraná. Para mais detalhes sobre o método de cálculo, ver Soares \& Porto (2012).
} 
Além disso, os efeitos crônicos decorrentes da exposição contínua ao produto, ainda que em baixas doses, não são contabilizados por causa da dificuldade de identificar relação direta entre exposição de agrotóxicos e doenças. Conforme Carneiro et al. (2015), não existem meios disponíveis para que sejam feitos estudos que avaliem os efeitos da exposição aos agrotóxicos por meio de resíduos em alimentos e na água.

Nesse contexto, o presente estudo analisa os efeitos agudos provenientes da exposição a agrotóxicos. Assim, tem-se como hipótese que a intensificação no uso de pesticidas aumenta as intoxicações nos estabelecimentos agropecuários brasileiros. Para testar essa hipótese, tem-se como objetivo verificar a relação entre a intensidade do uso de agrotóxicos e o número de intoxicações nos estabelecimentos agropecuários do Brasil.

Este estudo, além de contribuir com a literatura ao fazer uma análise em âmbito nacional, fornece informações úteis para que haja elaboração e efetiva implementação de políticas direcionadas à regulamentação do uso de agrotóxicos, aprimorando estratégias de fiscalização e conscientização a fim de promover o uso e o manuseio corretos desses produtos, mitigando os danos causados à saúde dos trabalhadores rurais e ligados às indústrias químicas.

O artigo está estruturado em mais três seções, além desta introdução. Na segunda seção, apresentam-se a estratégia empírica e a fonte de dados utilizadas na pesquisa; em seguida, na terceira seção, os resultados são apresentados e discutidos; por fim, na quarta seção, fazse a conclusão do trabalho.

\section{Estratégia empírica}

Um dos problemas encontrados pelos pesquisadores que buscam verificar os impactos causados pelo uso de agrotóxicos é que a intensidade do emprego desse insumo agrícola não ocorre de forma aleatória. As características do produtor, do estabelecimento agropecuário e do contexto social em que está inserido podem influenciar a intensidade do seu uso, ou seja, a decisão tomada pelo agricultor pode ser influenciada pela idade (Rahman, 2015; Mariyono et al., 2018; Zhang et al., 2018; Hashemi et al., 2012), pelo gênero (Rahman \& Chima, 2018; Sheahan \& Barrett, 2017), pelo nível de escolaridade (Jallow et al., 2017; Mariyono et al., 2018; Zhang et al., 2018; Sankoh et al., 2016), pela condição do produtor em relação à terra (Dasgupta et al., 2001), pela obtenção de crédito agrícola (Rahman, 2003), pelo recebimento de orientação técnica (Sankoh et al., 2016; Jallow et al., 2017), pela associação a cooperativas ou entidades de classe (Jin et al., 2015), pela utilização de agricultura orgânica (Soares \& Porto, 2012; Rahman, 2015), pelo tamanho da propriedade (Dasgupta et al., 2001; Rahman, 2003; Bürger et al., 2012), pelo grau de aversão ao risco e pela adesão a normas sociais (Hou et al., 2020; Bagheri et al., 2019).

Assim, para encontrar os efeitos da intensidade do uso de pesticidas sobre os casos de intoxicação nos estabelecimentos agropecuários, é preciso levar em consideração o possível viés de seleção causado por tais características. A simples comparação entre grupos de tratamento e controle pode implicar resultados tendenciosos, haja vista a possível heterogeneidade existente entre os grupos, o que pode, inclusive, afetar os resultados (Rosenbaum \& Rubin, 1983).

Dado que um experimento ideal, em que a utilização desse insumo fosse distribuída aleatoriamente entre os municípios, não é factível, utiliza-se de um modelo que permite a construção de um cenário de quase experimento, possibilitando a comparação entre municípios suficientemente semelhantes. Como apresentado por Bia \& Mattei (2008), as técnicas de escores de propensão têm sido bastante utilizadas nesses casos. Isso porque essas técnicas solucionam um dos principais problemas encontrados na avaliação de tratamento: a inexistência de informações dos tratados caso não tivessem recebido tratamento, impossibilitando a comparação 
da mesma unidade em situações distintas (tratada e não tratada) (Caliendo \& Kopeinig, 2008). Isso posto, o objetivo é obter um contrafatual (grupo controle) o mais semelhante possível do grupo tratado, em que a diferença entre os grupos seja somente em relação ao tratamento (Rosenbaum \& Rubin, 1983).

Para encontrar esse grupo, utilizou-se do Propensity Score Generalizado (PSG), por meio do qual se obtêm as funções dose-resposta e o efeito de tratamento (Imbens, 2000, Hirano \& Imbens, 2005). Vale mencionar que esse método tem sido utilizado em diversos contextos (Lima et al., 2020; Li et al., 2019; Oliveira et al., 2018; Bia \& Mattei, 2007). A seguir, apresentase, de forma sucinta, o método utilizado.

\subsection{Obtenção da função dose-resposta}

O PSG é uma extensão do método de escore de propensão (propensity score) elaborado por Rosenbaum e Rubin (1983) para os casos em que a variável tratamento é contínua (Imbens, 2000, Hirano \& Imbens, 2005). Considerando que a variável utilizada nesta pesquisa é a intensidade do uso de agrotóxicos, o PSG torna-se o método apropriado para identificar os efeitos dos agrotóxicos sobre a saúde da população. Esse método ainda permite verificar se esses efeitos ocorrem de forma heterogênea para diferentes níveis de tratamento.

Para demonstração do método, supõe-se uma amostra composta por $N$ municípios ( $i=1$, ..., $M$ ) e que $Y_{i}(t)$ representa o resultado potencial da unidade isob o nível de tratamento $t$, que, nesta pesquisa, refere-se à intensidade do uso de agrotóxicos. O objetivo é estimar a função dose-resposta média, representada por $\mu(t)=E\left[Y_{i}(t)\right], \forall t>0$. Para cada município, observam-se um vetor de covariáveis $\left(X_{j}\right)$, o nível de tratamento recebido $\left(T_{i}\right)$ e o resultado para o nível de tratamento recebido $\left(Y_{i}=Y_{i}\left(T_{i}\right)\right)$.

Por meio do PSG, obtém-se a função dose-resposta, que é baseada na estimação da probabilidade de cada nível de tratamento $\left(T_{i}=t\right)$, dado por $r(t, X)$. Analogamente ao Propensity Score Matching(PSM), o PSG atende à propriedade de balanceamento, ou seja, para municípios com o mesmo escore de propensão $(r(t, X))$, a probabilidade de se ter determinada intensidade do uso de agrotóxicos $(T=t)$ independe de suas características $(X)$, isto é, $X \perp 1\{T=t\} \mid r(t, x)$. Isso implica que, ao utilizar o PSG, é possível eliminar o viés associado às diferenças nas covariáveis, ou seja, o método controla o viés de seleção em observáveis.

Outra característica do PSG diz respeito à hipótese de ignorabilidade fraca, em que se assume independência condicional para cada valor de tratamento $(Y(t) \perp T \mid X, \forall t)$, ou seja, para dada probabilidade de receber o tratamento, o status de tratamento $t$ independe do resultado da intervenção (Hirano \& Imbens, 2005). Em outras palavras, o nível de tratamento recebido independe do resultado potencial condicional às covariáveis observáveis.

Diante disso, o método permite que a comparação seja feita entre municípios com características semelhantes, mas com diferentes níveis de tratamento. Sendo assim, é possível identificar se os efeitos da intensidade do uso de agrotóxicos são distintos entre os municípios que utilizam esse insumo agrícola de forma mais e menos intensiva.

O procedimento para estimar as funções dose-resposta é composto por três etapas. Inicialmente, para estimar o escore de propensão, $r_{i}\left(t, X_{i}\right)$, assume-se que o tratamento (intensidade do uso de agrotóxicos), condicional às covariáveis², tem uma distribuição normal, ou seja, $T_{i} \mid X_{i} \sim N\left(\beta_{0}+\beta_{1}^{\prime} X_{i}, \sigma^{2}\right)$. Os parâmetros $\beta_{0}, \beta_{1} e \sigma^{2}$ são estimados por máxima verossimilhança. O PSG é estimado pela função apresentada a seguir:

\footnotetext{
2 As variáveis utilizadas neste estudo são descritas no Quadro 1, na seção 2.2.
} 


$$
\hat{R}_{i}=\frac{1}{\sqrt{2 \pi \hat{\sigma}^{2}}} \exp \left(-\frac{1}{2 \hat{\sigma}^{2}}\left(T_{i}-\hat{\beta}_{0}-\hat{\beta}_{1}^{\prime} X_{i}\right)^{2}\right)
$$

Assumindo que a propriedade de balanceamento foi atendida, na segunda etapa estima-se a expectativa condicional do resultado $\left(Y_{i}\right)$, que, neste estudo, refere-se à proporção de pessoas intoxicadas nos estabelecimentos agropecuários, em função do nível de tratamento $\left(T_{i}\right)$ e do $\hat{r}_{i}\left(t, X_{i}\right)$, ou seja, obtém-se $E\left[Y_{i} \mid T_{i}, \hat{r}_{i}\right]$. Utilizando uma aproximação quadrática, tem-se que,

$E\left[Y_{i} \mid T_{i}, \hat{r}_{i}\right]=\alpha_{0}+\alpha_{1} f\left(T_{i}\right)+\alpha_{2} f\left(T_{i}\right)^{2}+\alpha_{3} \hat{r}_{i}+\alpha_{4} \hat{r}_{i}^{2}+\alpha_{5} f\left(T_{i}\right) \hat{r}_{i}$

Conforme Hirano e Imbens (2004), os parâmetros $\alpha$ não possuem interpretação convencional. Deste modo, na terceira etapa, utilizando os parâmetros estimados na Equação 2, obtém-se o resultado potencial médio para cada nível de tratamento, isto é, a função dose-resposta, conforme apresentado a seguir:

$$
\hat{E}[Y(\tilde{T})]=\frac{1}{N} \sum_{i=1}^{N} \hat{\alpha}_{0}+\hat{\alpha}_{1} f\left(\tilde{T}_{i}\right)+\hat{\alpha}_{2} f\left(\tilde{T}_{i}\right)^{2}+\hat{\alpha}_{3} \tilde{r}_{i}\left(\tilde{T}_{i}\right)+\hat{\alpha}_{4} \tilde{r}_{i}^{2}\left(\tilde{T}_{i}\right)+\hat{\alpha}_{5} \tilde{r}_{i}\left(\tilde{T}_{i}\right)
$$

Portanto, por meio da Equação 3, é possível observar a proporção de estabelecimentos com pessoas intoxicadas para cada nível de agrotóxicos utilizados. Adicionalmente, após a obtenção dos efeitos dose-resposta, calcula-se a derivada de $\hat{E}[Y(\tilde{T})]$ para verificar o efeito de um incremento marginal na intensidade do uso de agrotóxicos sobre a proporção de estabelecimentos rurais com pessoas intoxicadas.

\subsection{Fonte e tratamento dos dados}

Os dados utilizados nesta pesquisa estão em âmbito municipal e foram obtidos no Censo Agropecuário 2006³ , do Instituto Brasileiro de Geografia e Estatística (IBGE). Para as estimativas, buscou-se incluir um número expressivo de variáveis, dado que o método utilizado controla apenas o viés de seleção em observáveis. As variáveis utilizadas e suas respectivas descrições são apresentadas no Quadro 1.

\begin{tabular}{|c|c|}
\hline Variáveis & Descrição das variáveis \\
\hline Intoxicações & $\begin{array}{l}\text { Percentual de estabelecimentos agropecuários com pessoas } \\
\text { intoxicadas por agrotóxicos. }\end{array}$ \\
\hline Sexo (homens) & Percentual de estabelecimentos agropecuários cujo dirigente é homem. \\
\hline Idade_25 & $\begin{array}{l}\text { Percentual de estabelecimentos agropecuários cujo dirigente tem } \\
\text { menos de } 25 \text { anos. }\end{array}$ \\
\hline Idade_25a35 & $\begin{array}{l}\text { Percentual de estabelecimentos agropecuários cujo dirigente tem entre } \\
25 \text { e } 35 \text { anos. }\end{array}$ \\
\hline Idade_35a45* & $\begin{array}{l}\text { Percentual de estabelecimentos agropecuários cujo dirigente tem entre } \\
35 \text { e } 45 \text { anos. }\end{array}$ \\
\hline
\end{tabular}

Quadro 1: Descrição das variáveis utilizadas nas estimativas

Fonte: elaborado pelos autores conforme dados do Censo Agropecuário 2006 (Instituto Brasileiro de Geografia e Estatística, 2006). Nota: * Variáveis utilizadas como categoria base nas estimativas.

${ }^{3}$ Embora as informações do Censo Agropecuário 2017 estejam disponíveis, diferentemente do Censo Agropecuário 2006, não há uma pergunta sobre a existência de pessoas intoxicadas no estabelecimento agropecuário. Assim, para realizar este estudo, utilizou-se do Censo Agropecuário 2006 sem perda de sentido da análise, uma vez que se trata de uma análise mais agregada e estrutural. 
Quadro 1: Continuação...

\begin{tabular}{|c|c|}
\hline Variáveis & Descrição das variáveis \\
\hline Idade_45a55 & $\begin{array}{l}\text { Percentual de estabelecimentos agropecuários cujo dirigente tem entre } \\
45 \text { e } 55 \text { anos. }\end{array}$ \\
\hline Idade_55a65 & $\begin{array}{l}\text { Percentual de estabelecimentos agropecuários cujo dirigente tem entre } \\
55 \text { e } 65 \text { anos. }\end{array}$ \\
\hline Idade_65 & $\begin{array}{l}\text { Percentual de estabelecimentos agropecuários cujo dirigente tem mais } \\
\text { de } 65 \text { anos. }\end{array}$ \\
\hline Analfabeto* & $\begin{array}{l}\text { Percentual de estabelecimentos agropecuários cujo dirigente é } \\
\text { analfabeto. }\end{array}$ \\
\hline Lê e escreve & $\begin{array}{l}\text { Percentual de estabelecimentos agropecuários cujo dirigente sabe ler e } \\
\text { escrever. }\end{array}$ \\
\hline ef_incompleto & $\begin{array}{l}\text { Percentual de estabelecimentos agropecuários cujo dirigente possui } \\
\text { ensino fundamental incompleto. }\end{array}$ \\
\hline ef_completo & $\begin{array}{l}\text { Percentual de estabelecimentos agropecuários cujo dirigente possui } \\
\text { ensino fundamental completo. }\end{array}$ \\
\hline em_completo & $\begin{array}{l}\text { Percentual de estabelecimentos agropecuários cujo dirigente possui } \\
\text { ensino médio completo. }\end{array}$ \\
\hline Técnico agrícola & $\begin{array}{l}\text { Percentual de estabelecimentos agropecuários cujo dirigente possui a } \\
\text { formação de técnico agrícola. }\end{array}$ \\
\hline es_completo & $\begin{array}{l}\text { Percentual de estabelecimentos agropecuários cujo dirigente possui } \\
\text { ensino superior completo. }\end{array}$ \\
\hline exp_1 & $\begin{array}{l}\text { Percentual de estabelecimentos agropecuários cujo dirigente está no } \\
\text { comando da atividade há menos de um ano. }\end{array}$ \\
\hline exp_1a5 & $\begin{array}{l}\text { Percentual de estabelecimentos agropecuários cujo dirigente está no } \\
\text { comando da atividade há mais de um ano e menos de cinco anos. }\end{array}$ \\
\hline exp_5a10 & $\begin{array}{l}\text { Percentual de estabelecimentos agropecuários cujo dirigente está no } \\
\text { comando da atividade há mais de cinco anos e menos de dez anos. }\end{array}$ \\
\hline exp_10* & $\begin{array}{l}\text { Percentual de estabelecimentos agropecuários cujo dirigente está no } \\
\text { comando da atividade há mais de dez anos. }\end{array}$ \\
\hline Proprietário* & $\begin{array}{l}\text { Percentual de estabelecimentos agropecuários cujo dirigente é } \\
\text { proprietário da terra. }\end{array}$ \\
\hline Arrendatário & $\begin{array}{l}\text { Percentual de estabelecimentos agropecuários cujo dirigente é } \\
\text { arrendatário da terra. }\end{array}$ \\
\hline Parceiro & $\begin{array}{l}\text { Percentual de estabelecimentos agropecuários cujo dirigente é } \\
\text { parceiro. }\end{array}$ \\
\hline Ocupante & $\begin{array}{l}\text { Percentual de estabelecimentos agropecuários cujo dirigente é } \\
\text { ocupante. }\end{array}$ \\
\hline Associado & $\begin{array}{l}\text { Percentual de estabelecimentos agropecuários em que o produtor é } \\
\text { associado à cooperativa e/ou à entidade de classe. }\end{array}$ \\
\hline Financiamento & $\begin{array}{l}\text { Percentual de estabelecimentos agropecuários que obtiveram } \\
\text { financiamento. }\end{array}$ \\
\hline Orientação técnica & $\begin{array}{l}\text { Percentual de estabelecimentos agropecuários que receberam } \\
\text { orientação técnica. }\end{array}$ \\
\hline Qualificação & $\begin{array}{l}\text { Percentual de estabelecimentos agropecuários com presença de mão } \\
\text { de obra qualificada. }\end{array}$ \\
\hline Agricultura familiar & $\begin{array}{l}\text { Percentual de estabelecimentos agropecuários que fazem parte da } \\
\text { agricultura familiar. }\end{array}$ \\
\hline
\end{tabular}

Fonte: elaborado pelos autores conforme dados do Censo Agropecuário 2006 (Instituto Brasileiro de Geografia e Estatística, 2006). Nota: * Variáveis utilizadas como categoria base nas estimativas. 
Quadro 1: Continuação...

\begin{tabular}{|l|l|}
\hline \multicolumn{2}{|c|}{ Variáveis } \\
Agricultura orgânica & $\begin{array}{l}\text { Percentual de estabelecimentos agropecuários que realizaram } \\
\text { agricultura orgânica. }\end{array}$ \\
\hline Minifúndios** & $\begin{array}{l}\text { Percentual de estabelecimentos agropecuários cuja área é inferior a } 10 \\
\text { hectares. }\end{array}$ \\
\hline Pequena propriedade & $\begin{array}{l}\text { Percentual de estabelecimentos agropecuários cuja área é superior a } \\
10 \text { hectares e inferior a 50 hectares. }\end{array}$ \\
\hline Média propriedade & $\begin{array}{l}\text { Percentual de estabelecimentos agropecuários cuja área é superior a } \\
50 \text { hectares e inferior a 500 hectares. }\end{array}$ \\
\hline Grande propriedade* & $\begin{array}{l}\text { Percentual de estabelecimentos agropecuários cuja área é superior a } \\
500 \text { hectares. }\end{array}$ \\
\hline $\begin{array}{l}\text { Intensidade do uso de } \\
\text { agrotóxicos (R\$ha) }\end{array}$ & $\begin{array}{l}\text { Refere-se à razão entre as despesas com agrotóxicos e a área destinada } \\
\text { ao cultivo de lavouras permanentes e temporárias. }\end{array}$ \\
\hline
\end{tabular}

Fonte: elaborado pelos autores conforme dados do Censo Agropecuário 2006 (Instituto Brasileiro de Geografia e Estatística, 2006). Nota: * Variáveis utilizadas como categoria base nas estimativas.

Selecionaram-se variáveis que, conforme apresentado na literatura, poderiam influenciar a intensidade do uso de agrotóxicos. Sendo assim, ao incluí-las no modelo, o objetivo foi tornar o grupo tratado o mais semelhante possível do grupo controle, reduzindo ao máximo o viés de seleção.

Deste modo, uma das variáveis inseridas no modelo foi o gênero do dirigente do estabelecimento rural. Sheahan \& Barrett (2017) revelam que o gênero influencia a decisão de aplicar insumos modernos, como os pesticidas. Já Rahman \& Chima (2018) demonstram que os agricultores do sexo masculino utilizam mais pesticidas quando comparados com as mulheres.

A idade é outro fator que pode afetar a intensidade do uso de agrotóxicos. Segundo Mariyono et al. (2018), a habilidade de previsão do nível de limiar econômico das pragas pode ser limitada para agricultores mais velhos, que passam a utilizar os pesticidas como medida preventiva, e não de controle, resultando na maior intensidade do seu uso. Zhang et al. (2018) demonstram que a idade do produtor está negativamente relacionada com a disposição de reduzir o uso de pesticidas.

O nível de escolaridade também pode afetar a intensidade do uso de agrotóxicos. Os estudos realizados por Jallow et al. (2017), Mariyono et al. (2018) e Zhang et al. (2018) apontam que níveis mais elevados de educação reduzem a intensidade do uso de pesticidas.

Ao mesmo tempo, a experiência dos produtores na atividade agrícola, que, nesta pesquisa, corresponde aos anos que os dirigentes estão no comando da atividade, pode afetar a intensidade do uso de agrotóxicos. Isso porque, conforme Hashemi et al. (2012), quanto mais tempo na atividade, maior a percepção dos agricultores em relação aos riscos associados ao uso de agrotóxicos.

Outra característica potencialmente relacionada com a intensidade do uso de pesticidas é a condição do produtor em relação à terra (proprietário, arrendatário, parceiro e ocupante). Segundo Dasgupta et al. (2001), os direitos de propriedade sinalizam uma estrutura de incentivos que influencia de maneira significativa a gestão ambiental, o que pode afetar a intensidade do uso de pesticidas.

O financiamento, ou crédito agrícola, também influencia o uso de agrotóxicos (Rahman, 2003). No Brasil, a relevância dessa variável está associada ao modelo agrícola adotado no país, que utilizou o crédito agrícola como um dos instrumentos para incentivar o uso intensivo de agroquímicos (Porto \& Soares, 2012). 
A orientação em relação ao uso de agrotóxicos e o conhecimento de alternativas para o manejo de pragas são fatores que podem influenciar significativamente a intensidade do uso de pesticidas (Abadi, 2018; Hou et al., 2020). Deste modo, os serviços de assistência técnica e extensão rural (ATER), representados pela variável orientação técnica, são considerados no modelo.

Assim como os serviços de ATER, as cooperativas podem exercer influência significativa na intensidade do uso de agrotóxicos. Conforme jin et al. (2015), agricultores cooperados obtêm informações mais precisas sobre a dosagem dos pesticidas em relação aos não cooperados, e a precisão dessas informações é determinante para o uso menos intensivo desses compostos químicos. Concomitantemente, a presença de mão de obra qualificada nos estabelecimentos pode auxiliar no uso adequado de pesticidas, interferindo na intensidade de seu uso.

A variável agricultura familiar é considerada, haja vista sua participação relevante no setor agrícola brasileiro, com representação, em 2006, de cerca de $84 \%$ dos estabelecimentos agropecuários (Instituto Brasileiro de Geografia e Estatística, 2006). Ademais, observa-se a disseminação do uso de agroquímicos nesses estabelecimentos (Valadares et al., 2020).

Outro fator que pode influenciar a intensidade do uso de agrotóxicos é a agricultura orgânica, que não utiliza produtos químicos sintéticos no seu processo produtivo. Conforme Soares \& Porto (2012) e Rahman (2015), a agricultura orgânica tem apresentado resultados satisfatórios, sendo uma alternativa ao cultivo químico-dependente.

Por fim, considera-se o tamanho das propriedades rurais ${ }^{4}$, dada sua potencial relação com a intensidade do uso de agrotóxicos, sendo uma variável frequentemente utilizada em pesquisas relacionadas ao tema (Dasgupta et al., 2001; Rahman, 2003; Bürger et al., 2012; Ghimire \& Woodward, 2013; Mariyono et al., 2018).

Para identificar os impactos da intensidade do uso de agrotóxicos na saúde, utilizou-se, como proxy, da proporção dos estabelecimentos com pessoas intoxicadas. Essa variável está disponível no Censo Agropecuário $2006^{5}$, que averiguou a existência de pessoas intoxicadas por agrotóxicos nos estabelecimentos agropecuários brasileiros. Vale ressaltar que, dos 5.548 municípios analisados em 2006, 58,68\% apresentaram ao menos um estabelecimento com pessoas intoxicadas. Relatou-se a presença de pessoas intoxicadas em 25.008 propriedades rurais (Instituto Brasileiro de Geografia e Estatística, 2006). Já a variável tratamento, que se refere à intensidade do uso de agrotóxicos ( $)$, foi construída da seguinte forma:

$I=\frac{\text { Despesas comagrotóxicos }}{\text { Area produtiva }}$

Em que: as despesas com agrotóxicos são medidas em reais ( $R$ \$); e a área produtiva corresponde à área do estabelecimento destinada a lavouras e pastagens, em hectares (ha).

Ressalta-se que foram excluídos os municípios onde a intensidade do uso de agrotóxicos foi inferior a $R \$ 1,00 /$ ha e superior a $R \$ 1.000,00 /$ ha. Logo, a amostra foi composta por 4.310 municípios brasileiros, totalizando 3.941.564 estabelecimentos agropecuários.

\section{Resultados e discussão}

${ }^{4}$ No Brasil, houve a expansão da aquisição de chácaras e sítios pela população urbana (Hoffman \& Ney, 2010). Deste modo, para atenuar o possível viés causado pela presença de estabelecimentos destinados ao lazer dos proprietários, é importante considerar minifúndios com tamanho, no mínimo, superior a 0,1 ha. Diante disso, realizaram-se estimativas adicionais considerando essa estratificação. Como os resultados foram muito semelhantes, a estratificação apresentada no Quadro 1 foi utilizada.

${ }^{5}$ Como mencionado, o Censo Agropecuário 2017 não disponibilizou informação sobre a existência de pessoas intoxicadas nos estabelecimentos agropecuários, o que restringiu esta análise para o ano de 2006. 


\subsection{Intoxicação por agrotóxicos e características dos municípios brasileiros}

Nesta seção, apresentam-se algumas características dos municípios brasileiros que compõem a amostra. A Tabela 1 mostra as estatísticas descritivas das variáveis utilizadas na análise de acordo com a existência ou não de estabelecimentos com pessoas intoxicadas no município.

Tabela 1: Estatísticas descritivas das variáveis utilizadas no modelo por municípios com intoxicação nos estabelecimentos agropecuários e no Brasil, 2006

\begin{tabular}{|c|c|c|c|c|c|c|}
\hline \multirow[t]{2}{*}{ Variáveis } & \multicolumn{2}{|c|}{$\begin{array}{c}\text { Municípios com } \\
\text { pessoas intoxicadas } \\
\text { nos estabelecimentos } \\
\text { rurais }\end{array}$} & \multicolumn{2}{|c|}{$\begin{array}{l}\text { Municípios sem pessoas } \\
\text { intoxicadas nos } \\
\text { estabelecimentos rurais }\end{array}$} & \multicolumn{2}{|c|}{ Brasil } \\
\hline & Média & DP & Média & DP & Média & DP \\
\hline Sexo (homens) & 89,42 & 5,80 & 89,74 & 5,24 & 89,53 & 5,62 \\
\hline $\begin{array}{l}\text { Idade até } 25 \\
\text { anos }\end{array}$ & 2,56 & 1,87 & 1,92 & 1,67 & 2,34 & 1,83 \\
\hline $\begin{array}{l}\text { Idade de } 25 \text { a } \\
35 \text { anos }\end{array}$ & 11,80 & 4,47 & 9,78 & 4,53 & 11,11 & 4,59 \\
\hline $\begin{array}{l}\text { Idade de } 35 \text { a } \\
45 \text { anos }\end{array}$ & 22,10 & 3,76 & 20,25 & 4,64 & 21,47 & 4,17 \\
\hline $\begin{array}{l}\text { Idade de } 45 \text { a } \\
55 \text { anos }\end{array}$ & 24,87 & 3,82 & 25,35 & 4,52 & 25,03 & 4,08 \\
\hline $\begin{array}{l}\text { Idade de } 55 \text { a } \\
65 \text { anos }\end{array}$ & 21,23 & 3,52 & 22,42 & 4,63 & 21,63 & 3,97 \\
\hline $\begin{array}{l}\text { Idade mais de } \\
65 \text { anos }\end{array}$ & 17,45 & 5,31 & 20,29 & 6,23 & 18,41 & 5,79 \\
\hline Analfabeto & 16,55 & 17,67 & 11,54 & 14,12 & 14,85 & 16,71 \\
\hline Lê e escreve & 7,08 & 6,77 & 6,46 & 7,53 & 6,87 & 7,04 \\
\hline ef_incompleto & 48,01 & 17,97 & 41,99 & 14,51 & 45,96 & 17,11 \\
\hline ef_completo & 10,51 & 6,08 & 12,71 & 7,53 & 11,26 & 6,69 \\
\hline em_completo & 7,62 & 5,16 & 11,12 & 6,86 & 8,81 & 6,02 \\
\hline $\begin{array}{l}\text { Técnico } \\
\text { agrícola }\end{array}$ & 1,80 & 1,66 & 2,46 & 2,45 & 2,02 & 1,99 \\
\hline es_completo & 4,02 & 4,78 & 8,29 & 8,42 & 5,47 & 6,58 \\
\hline exp_1 & 2,84 & 2,84 & 3,26 & 3,08 & 2,98 & 2,93 \\
\hline exp_1a5 & 17,44 & 7,45 & 18,92 & 8,57 & 17,94 & 7,88 \\
\hline exp_5a10 & 17,93 & 7,19 & 19,27 & 7,84 & 18,39 & 7,44 \\
\hline exp_10 & 61,79 & 13,21 & 58,54 & 13,78 & 60,69 & 13,49 \\
\hline Proprietário & 79,87 & 16,63 & 84,45 & 14,55 & 81,43 & 16,10 \\
\hline Arrendatário & 4,98 & 6,03 & 4,79 & 6,43 & 4,91 & 6,17 \\
\hline Parceiro & 2,37 & 4,66 & 1,41 & 3,26 & 2,04 & 4,26 \\
\hline Ocupante & 5,92 & 7,67 & 4,07 & 7,04 & 5,29 & 7,52 \\
\hline Associado & 44,13 & 22,49 & 31,72 & 20,68 & 39,91 & 22,67 \\
\hline Financiamento & 23,09 & 16,46 & 13,56 & 9,52 & 19,85 & 15,16 \\
\hline $\begin{array}{l}\text { Orientação } \\
\text { técnica }\end{array}$ & 33,67 & 24,05 & 34,82 & 22,92 & 34,06 & 23,67 \\
\hline Qualificação & 5,47 & 9,40 & 6,31 & 11,00 & 5,75 & 9,98 \\
\hline
\end{tabular}

Fonte: elaborado pelos autores conforme dados Censo Agropecuário 2006 (Instituto Brasileiro de Geografia e Estatística, 2006). Nota: ef incompleto: ensino fundamental incompleto; ef completo: ensino fundamental completo; em _completo: ensino médio completo; es_completo: ensino superior complēto; exp_1: dirigente no comando da atividade há menos de um ano; exp_1 a5: dirigente no comando da atividade há mais de um ano e menos de cinco anos; exp_5a10: dirigente no comando da atividade há mais de cinco anos e menos de dez anos; exp_10: dirigente no comando da atividade há mais de dez anos. Todas as variáveis, exceto intensidade do uso de agrotóxicos, foram apresentadas em percentual de estabelecimentos agropecuários. 
Tabela 1: Continuação...

\begin{tabular}{|c|c|c|c|c|c|c|}
\hline \multirow[t]{2}{*}{ Variáveis } & \multicolumn{2}{|c|}{$\begin{array}{c}\text { Municípios com } \\
\text { pessoas intoxicadas } \\
\text { nos estabelecimentos } \\
\text { rurais }\end{array}$} & \multicolumn{2}{|c|}{$\begin{array}{l}\text { Municípios sem pessoas } \\
\text { intoxicadas nos } \\
\text { estabelecimentos rurais }\end{array}$} & \multicolumn{2}{|c|}{ Brasil } \\
\hline & Média & DP & Média & DP & Média & DP \\
\hline $\begin{array}{l}\text { Agricultura } \\
\text { familiar }\end{array}$ & 81,32 & 12,96 & 70,74 & 17,08 & 77,73 & 15,33 \\
\hline $\begin{array}{l}\text { Agricultura } \\
\text { orgânica }\end{array}$ & 1,52 & 2,55 & 2,44 & 5,17 & 1,83 & 3,68 \\
\hline Minifúndios & 42,57 & 22,70 & 38,54 & 22,26 & 41,20 & 22,63 \\
\hline $\begin{array}{l}\text { Pequena } \\
\text { propriedade }\end{array}$ & 36,31 & 16,72 & 33,01 & 13,84 & 35,19 & 15,87 \\
\hline $\begin{array}{l}\text { Média } \\
\text { propriedade }\end{array}$ & 15,48 & 13,44 & 21,52 & 14,69 & 17,53 & 14,17 \\
\hline $\begin{array}{l}\text { Grande } \\
\text { propriedade }\end{array}$ & 2,39 & 5,66 & 4,20 & 7,51 & 3,00 & 6,40 \\
\hline $\begin{array}{l}\text { Intensidade } \\
\text { do uso de } \\
\text { agrotóxicos } \\
(\mathrm{R} \$ / \mathrm{ha})\end{array}$ & 56,42 & 84,27 & 44,72 & 76,92 & 52,45 & 82,02 \\
\hline Observações & & & & & & \\
\hline
\end{tabular}

Fonte: elaborado pelos autores conforme dados Censo Agropecuário 2006 (Instituto Brasileiro de Geografia e Estatística, 2006). Nota: ef_incompleto: ensino fundamental incompleto; ef_completo: ensino fundamental completo; em_completo: ensino médio completo; es_completo: ensino superior completo; exp_1: dirigente no comando da atividade há menos de um ano; exp 1a5: dirigente no comando da atividade há mais de um ano e menos de cinco anos; exp_5a10: dirigente no comando da atividade há mais de cinco anos e menos de dez anos; exp 10: dirigente no comando da atividade há mais de dez anos. Todas as variáveis, exceto intensidade do uso de agrotóxicos, foram apresentadas em percentual de estabelecimentos agropecuários.

Observa-se que os 1.464 municípios sem relatos de pessoas intoxicadas nos estabelecimentos rurais, que correspondem a cerca de $34 \%$ da amostra, apresentam, na média, dirigentes com maior nível de escolaridade e idade superior a 45 anos em comparação aos municípios onde há pessoas intoxicadas nos estabelecimentos, em 2006. Destaca-se que o percentual de estabelecimentos cujos dirigentes possuem ensino superior é mais que o dobro nos municípios sem pessoas intoxicadas em comparação aos municípios com pessoas intoxicadas. No entanto, esse percentual é pouco expressivo (inferior a 10\%). Os dirigentes de mais de 65\% dos estabelecimentos agropecuários brasileiros possuem, no máximo, ensino fundamental incompleto, o que é um indício de que a escolaridade pode influenciar o nível de intoxicação.

Nesse contexto, como apontado por Neves et al. (2020), é importante dizer que há extenso saber popular e tradicional entre os trabalhadores rurais, e, deste modo, não se pode considerar que a baixa escolaridade esteja, necessariamente, relacionada ao pouco conhecimento. No entanto, os autores ressaltam que esse conhecimento não pode ser aplicado aos agrotóxicos, o que exige conhecimento técnico e manejo adequado. Segundo Moreira et al. (2002), o baixo nível de escolaridade da população rural dificulta o entendimento das informações técnicas contidas nas embalagens dos produtos agroquímicos, sendo um dos fatores responsáveis pela intoxicação.

No que diz respeito à faixa etária, a maior presença de indivíduos com menos de 45 anos nos municípios com pessoas intoxicadas em relação aos municípios sem intoxicação pode ser por causa da predominância de trabalhadores rurais e aplicadores de agrotóxicos nessa faixa etária (Neves \& Bellini, 2013).

O maior percentual de estabelecimentos com mão de obra qualificada nos municípios sem pessoas intoxicadas ratifica a importância do conhecimento para minimizar os danos à saúde 
relacionados ao uso de agrotóxicos. De acordo com Sankoh et al. (2016), a falta de treinamento pode levar ao uso indevido dos pesticidas, aumentando os riscos à saúde e ao meio ambiente.

Outra questão que chama atenção diz respeito à condição do produtor em relação à terra. Embora a maior parte dos dirigentes seja proprietário, essa proporção é maior nos municípios sem intoxicação $(84,45 \%)$ em comparação àqueles com pessoas intoxicadas nas propriedades (79,87\%). Já a proporção de estabelecimentos em que os dirigentes são arrendatários, parceiros ou ocupantes é maior nos municípios com pessoas intoxicadas. Como se pode observar na Tabela 1, a menor diferença refere-se aos arrendatários, cuja proporção é de 4,98 e 4,79 nos municípios com e sem pessoas intoxicadas, respectivamente. Os parceiros estão presentes em $2,37 \%$ dos estabelecimentos rurais com pessoas intoxicadas e em 1,41\% das propriedades em que não há relato de intoxicação. Essa proporção é de, respectivamente, 5,92 e 4,07 para os dirigentes que são ocupantes.

Segundo Dasgupta et al. (2001), espera-se que o comportamento dos proprietários seja influenciado por seus interesses de longo prazo e que eles, desta forma, reduzam o uso de pesticidas de maior periculosidade ao ecossistema. Já os produtores que não têm a posse total da terra tendem a priorizar os rendimentos no curto prazo, podendo aplicar maiores quantidades de agrotóxicos com a expectativa de aumentar a produtividade.

Observa-se também diferenças significativas em relação ao financiamento rural. Em geral, o financiamento é superior em aproximadamente 10 p.p. nos municípios onde há estabelecimentos com pessoas intoxicadas em comparação àqueles onde não há intoxicação nas propriedades rurais, indicando uma possível relação entre crédito rural e intoxicação por agrotóxicos. Sabe-se que o modelo agrícola adotado no Brasil incentivou o uso intensivo de agroquímicos, inclusive por meio do crédito agrícola (Porto \& Soares, 2012). No entanto, diante dos prejuízos decorrentes do uso indiscriminado de pesticidas, torna-se necessária a revisão das condições e finalidade dos créditos ofertados.

A orientação técnica é, em geral, um pouco superior nos municípios onde não foram relatados casos de intoxicação nos estabelecimentos agropecuários relativamente aos municípios com pessoas intoxicadas. Destaca-se a baixa proporção de propriedades que obtiveram orientação técnica em 2006. Os serviços de ATER podem ser um instrumento eficaz para redução dos riscos à saúde dos trabalhadores rurais ao auxiliá-los no uso seguro dos agroquímicos e na adoção de técnicas e práticas sustentáveis.

Em relação ao percentual de estabelecimentos que fazem parte da agricultura familiar, ainda que a proporção seja significativa nos municípios que não têm pessoas intoxicadas nos estabelecimentos (70,74\%), esse valor é ainda maior nos municípios com pessoas intoxicadas $(81,32 \%)$. Considerando a proporção expressiva de propriedades que fazem parte da agricultura familiar (77,73\% na amostra analisada), ressalta-se a importância de políticas direcionadas a esse público. $O$ investimento em educação e na qualificação dos agricultores pode ser uma forma de atenuar o problema, dado que a baixa escolaridade, predominante na população rural, é um dos fatores de risco para a intoxicação (Soares \& Porto, 2009).

Com relação à intensidade do uso de agrotóxicos, a média dos municípios onde os estabelecimentos relataram casos de intoxicação ( $R$ \$ 56,42/ha) supera a dos municípios sem relato ( $R \$ 44,72 / \mathrm{ha}$ ), revelando uma potencial relação entre essa variável e a existência de pessoas intoxicadas nas propriedades rurais do município. Essa relação é verificada na seção a seguir.

\subsection{Impactos da intensidade do uso de agrotóxicos na saúde da população rural}

Nesta seção, apresentam-se os resultados obtidos por meio do PSG. Para obter as funções dose-resposta e o efeito de tratamento, estimou-se o modelo quadrático (Equação 2) e utilizou- 
se da transformação logarítmica do tratamento para que os resíduos fossem normalmente distribuídos.

Na Figura 1, observa-se que a relação entre intensidade do uso de agrotóxicos e proporção de estabelecimentos com pessoas intoxicadas é positiva, independentemente do nível de tratamento. À medida que a intensidade aumenta, maior é o impacto observado. Nos municípios onde os estabelecimentos gastam, em média, $R \$ 20,00 /$ ha com agrotóxicos, a proporção de estabelecimentos com pessoas intoxicadas ultrapassa $0,4 \%$. Para valores acima de $R \$ 100,00$ / ha, mais de $0,5 \%$ dos estabelecimentos apresentam pessoas intoxicadas. Tendo em vista que a média das despesas com agrotóxicos no Brasil é de $R \$ 52,45 /$ ha (Tabela 1), os resultados revelam que, de modo geral, há pessoas intoxicadas em mais de $0,45 \%$ dos estabelecimentos agropecuários brasileiros. Considerando a amostra analisada, conclui-se que, na média, há pessoas intoxicadas em 17.737 propriedades rurais.

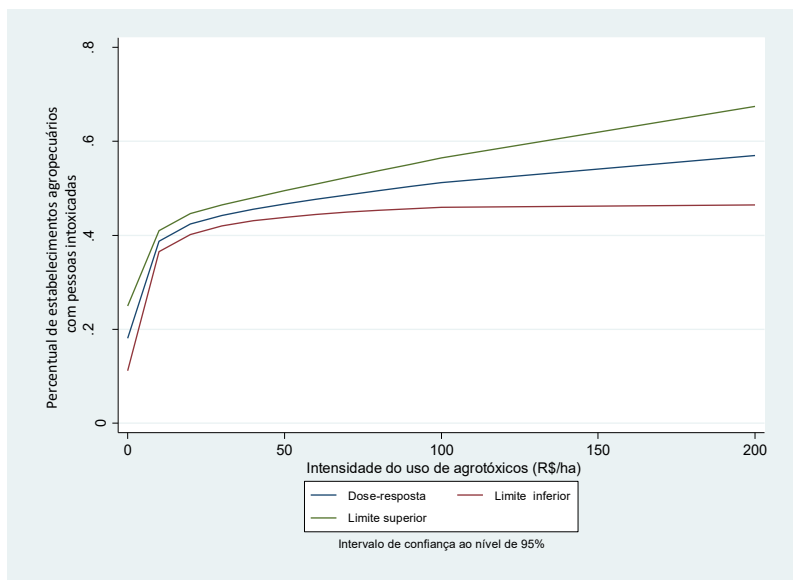

Figura 1: Impactos da intensidade do uso de agrotóxicos na saúde da população rural brasileira. Nota: os intervalos de confiança foram obtidos por bootstrap com 100 repetições. Número de observações: 4.310. Fonte: elaborada pelos autores a partir dos resultados da pesquisa, obtidos por meio do software Stata.

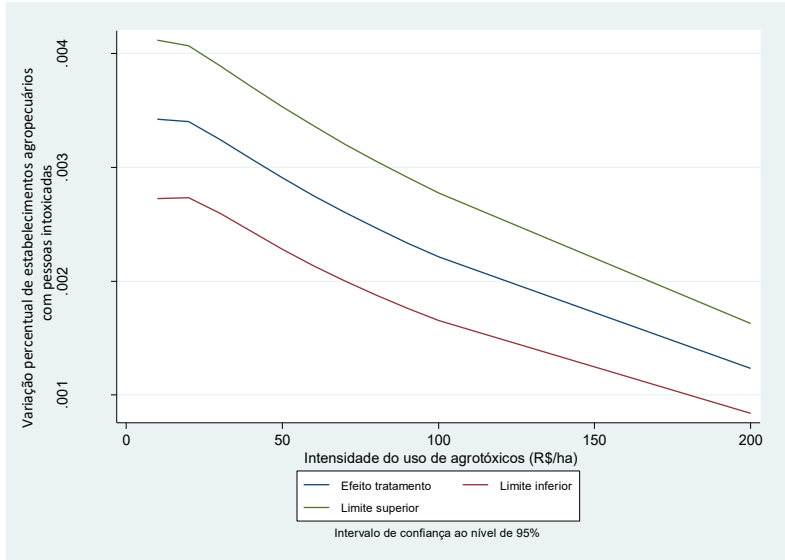

Figura 2: Efeitos marginais da intensidade do uso de agrotóxicos na saúde da população rural brasileira. Nota: os intervalos de confiança foram obtidos por bootstrap com 100 repetições. Número de observações: 4.310. Fonte: elaborada pelos autores a partir dos resultados da pesquisa, obtidos por meio do software Stata. 
Na Figura 2, observa-se que o efeito marginal de tratamento é constante até aproximadamente $\mathrm{R} \$ 25,00 /$ ha, em que o aumento de $\mathrm{R} \$ 10,00 /$ ha em despesas com agrotóxicos implica aumento superior a 0,03 p.p. na proporção de estabelecimentos com pessoas intoxicadas. A partir desse nível, o efeito marginal é decrescente, em que o aumento de R\$10,00/ha em despesas com agrotóxicos pode resultar no aumento de 0,034 p.p. a 0,012 p.p. na proporção desses estabelecimentos, para diferentes níveis de tratamento.

Ainda que haja redução do efeito marginal à medida que os agrotóxicos são usados mais intensamente, ele permanece positivo, ou seja, o número de casos de intoxicação nos estabelecimentos agropecuários é potencializado com a intensificação do uso de agrotóxicos.

Esses resultados corroboram os encontrados por Hu et al. (2015), que revelam relação consistente e positiva entre intensidade do uso de pesticidas e danos à saúde. Adicionalmente, os estudos de Kim et al. (2017), Sankoh et al. (2016), Pignati et al. (2014) e Pignati et al. (2017) encontraram correlação positiva entre problemas de saúde e uso de agrotóxicos.

Diante do exposto, destaca-se a necessidade de medidas que visem mitigar tais efeitos. Uma das questões fundamentais para o uso seguro de agrotóxicos é o conhecimento. Atender às especificidades necessárias para aplicação de pesticidas, como prazos de carência e dose adequada, é essencial para mitigação dos riscos à saúde.

Nesse contexto, salienta-se o baixo nível de escolaridade como um dos fatores de risco de intoxicação (Moreira et al., 2002; Soares \& Porto, 2009). Como apresentado na Tabela 1, o percentual de estabelecimentos agropecuários brasileiros cujo dirigente não possui ensino fundamental completo é cerca de 67\%. Esse percentual ultrapassa 70\% quando se consideram apenas os municípios com estabelecimentos em que há pessoas intoxicadas.

Segundo Soares et al. (2005), há um número significativo de produtores que se orientam pelo rótulo, e a baixa escolaridade de grande parte desses agricultores pode dificultar o entendimento das instruções técnicas em relação à forma de aplicação e à periculosidade dos agroquímicos. Sendo assim, é possível que esses agricultores utilizem pesticidas sem considerar as especificações técnicas, resultando no uso incorreto e excessivo desse insumo (Sankoh et al., 2016).

Diante disso, os serviços de ATER podem ser uma ferramenta eficaz para orientar os agricultores em relação ao manuseio, armazenamento e aplicação dos agrotóxicos, reduzindo seu uso indevido e os riscos à saúde. No entanto, como apresentado na Tabela 1, apenas 34,06\% dos estabelecimentos obtiveram orientação técnica em 2006. Conforme Soares \& Porto (2012), na ausência de ATER, as condições de uso de agroquímicos pelos agricultores são impróprias. Segundo Sankoh et al. (2016), a falta de treinamento e educação dos agricultores resulta na utilização dos agrotóxicos de forma aleatória. Consequentemente, os danos ao meio ambiente e à saúde são potencializados.

Soares \& Porto $(2009,2012)$ ressaltam a importância da prescrição de um agrônomo para o uso adequado e a redução do risco relacionado à utilização de pesticidas. Conforme Jallow et al. (2017), Jin et al. (2015) e Soares \& Porto (2009, 2012), seguir orientações de revendedores de agrotóxicos está associado ao sobreuso desses produtos, aumentando a probabilidade de intoxicação dos agricultores.

Cabe ainda destacar que o uso indiscriminado de agrotóxicos favorece o surgimento de resistência das pragas (Papa et al., 2014). Consequentemente, os agricultores utilizam maiores quantidades, concentrações mais altas e aplicações mais frequentes de pesticidas (Chandrasekara et al., 1985). Considerando que, quanto maior a intensidade do uso de agrotóxicos, maior o nível de intoxicação (Figura 1), ratifica-se a importância dos serviços de ATER para auxiliar os produtores na adoção de tecnologias mais sustentáveis e orientá-los 
quanto ao uso e ao manuseio corretos dos agroquímicos, mitigando os riscos relacionados ao seu uso.

Nesse ínterim, como apontado por Soares et al. (2005), para atenuar os danos à saúde, além de ações para capacitação dos trabalhadores rurais, é importante oferecer condições e alternativas agroecológicas para o manejo de pragas. Deste modo, concomitantemente com os investimentos nos serviços de ATER, o desenvolvimento de alternativas sustentáveis para o controle de pragas e patógenos, como o manejo integrado de pragas (MIP) e o manejo integrado de doenças (MID), torna-se importante para reduzir a intensidade do uso de agrotóxicos e seus impactos na saúde e no meio ambiente. Adicionalmente, programas que incentivem a agricultura orgânica podem contribuir para essa redução.

Conforme Soares \& Porto (2012), a agricultura orgânica tem se mostrado uma técnica eficiente, reduzindo o uso de pesticidas e mantendo a produção em determinadas culturas. Como resultado, as intoxicações por agrotóxicos tendem a diminuir. Conforme apresentado na Tabela 1, ainda que a agricultura orgânica seja pouco expressiva no Brasil, a proporção de estabelecimentos que a praticam é relativamente maior nos municípios sem pessoas intoxicadas nas propriedades rurais.

Vale mencionar que a agricultura orgânica, ao mesmo tempo que produz sem agrotóxicos, beneficia o meio ambiente, as relações trabalhistas, a cadeia produtiva e a saúde do trabalhador rural (Alencar et al., 2013), ou seja, com o objetivo de atingir um padrão sustentável de produção, o sistema de produção orgânico melhora a qualidade de vida das famílias por meio das interações agricultor-meio ambiente (Alencar et al., 2013).

Nesse contexto, ressalta-se a Política Nacional de Agroecologia e Produção Orgânica (PNAPO), instituída pelo Decreto n 7.794/2012, que tem como objetivo integrar, articular e adequar políticas, programas e ações indutoras da transição agroecológica e da produção orgânica e de base agroecológica, promovendo o uso sustentável de recursos naturais e a oferta de alimentos saudáveis e, consequentemente, colaborando para o desenvolvimento sustentável e para a melhor qualidade de vida da população (Brasil, 2012).

Como instrumentos da PNAPO, destacam-se o Programa de Aquisição de Alimentos (PAA) e o Plano Nacional de Alimentação Escolar (PNAE), que foram utilizados para promover a produção orgânica por meio do incentivo à aquisição de alimentos livres de agrotóxicos (Sambuichi et al., 2017). Diante disso, Cunha et al. (2017) ressaltam que, além dos benefícios econômico e social, esses programas beneficiam o meio ambiente, ao incentivarem a produção sem agrotóxicos, e a saúde das famílias, as quais melhoram sua alimentação com produtos de maior qualidade.

Além disso, é importante destacar a participação das instituições de ensino e pesquisa no desenvolvimento de técnicas de MIP e MID, que têm auxiliado os produtores rurais no controle de pragas e patógenos por meio de práticas menos nocivas ao meio ambiente e à saúde. Como exemplo, destaca-se a parceria da Embrapa Soja com a Emater Paraná, que intensificaram as ações de difusão do MIP na cultura de soja no estado, resultando em benefícios para os produtores locais, como a redução dos custos de produção e dos riscos à saúde e ao meio ambiente (Staback et al., 2020; Conte et al., 2019).

Adicionalmente, ressalta-se a contribuição de especialistas formados em universidades brasileiras para o desenvolvimento de métodos de controle biológico, um dos componentes do manejo integrado de pragas e doenças (Parra, 2014). Segundo Parra (2014), o estabelecimento dos programas de pós-graduação na década de 1960 no Brasil e a fundação da Embrapa no mesmo período mobilizaram recursos humanos em estudos de entomologia, favorecendo o avanço do controle biológico no país. Como resultado, o Brasil se tornou o líder mundial no uso 
de controle biológico nas lavouras, além de exportar a tecnologia para outros países (Empresa Brasileira de Pesquisa Agropecuária, 2019).

Diante do exposto, observa-se, no Brasil, alguns avanços em relação a medidas que contribuem para a redução do uso de agrotóxicos, como o desenvolvimento do controle biológico e políticas de incentivo à agricultura orgânica. No entanto, ao mesmo tempo que se verificam programas e políticas de incentivo ao desenvolvimento agrícola sustentável, observa-se um ritmo crescente na liberação de agroquímicos, batendo recordes consecutivos desde 2015 (Brasil, 2019).

Ainda que os resultados não abordem diretamente o impacto da liberação de agrotóxicos na intensidade do uso, é possível que esse aumento expressivo nos registros contribua para o uso excessivo e inadequado de pesticidas, fomentando as externalidades negativas causadas pelo seu uso, como os danos à saúde. Assim, para a alteração efetiva no uso de pesticidas, as políticas devem ser acompanhadas de regulação que vise ao desenvolvimento sustentável do setor agrícola. Além disso, é de suma importância considerar os riscos à saúde do trabalhador na formulação dessas políticas.

É importante destacar que este estudo considerou a existência de pessoas intoxicadas nos estabelecimentos rurais, mas se sabe que toda a população está sujeita a intoxicações por meio do consumo de água e alimentos ${ }^{6}$ contaminados com resíduos (Carneiro et al., 2015). Além disso, estudos têm demonstrado que o uso de agrotóxicos possui relação potencial com o desenvolvimento de doenças como câncer, malformação congênita, diabetes etc. (Instituto Nacional do Câncer, 2019). Sendo assim, os efeitos do uso de agrotóxicos podem ser ainda mais significativos no longo prazo, afetando, inclusive, o desenvolvimento do país por meio dos efeitos sobre o capital humano.

\section{Conclusões}

Este estudo fez uma análise da relação entre a intensidade do uso de agrotóxicos e a presença de pessoas intoxicadas nos estabelecimentos agropecuários brasileiros e identificou o efeito do aumento na intensidade do uso desse composto químico sobre as intoxicações.

Os resultados revelam que, quanto maior a intensidade do uso de agrotóxicos, maior o impacto na saúde da população residente nos estabelecimentos rurais brasileiros. Na média, municípios onde as despesas com agrotóxicos superam $R \$ 20,00 /$ ha possuem pessoas intoxicadas em mais de $0,4 \%$ de seus estabelecimentos agropecuários. Tendo em vista que a média das despesas com agrotóxicos no Brasil é de $\mathrm{R} \$ 52,45 /$ ha, constatou-se que há pessoas intoxicadas em mais de $0,45 \%$ das propriedades rurais brasileiras. Além disso, verificou-se que o efeito marginal de tratamento, embora seja decrescente, é positivo e estatisticamente significativo, independentemente da intensidade do uso de agrotóxicos.

Em suma, conclui-se que o uso excessivo e inadequado de pesticidas tem efeitos significativos sobre os casos de intoxicação nos estabelecimentos agropecuários brasileiros. Ressalta-se que o modelo agrícola adotado no país tem contribuído para o uso intensivo de agroquímicos. Nesse sentido, torna-se necessário repensar esse modelo para que o Brasil alcance o desenvolvimento sustentável. Programas que incentivem a adoção de práticas ecologicamente corretas, como o MIP e o MID, em conjunto com a orientação técnica, devem ser formulados. Além disso, é necessário haver programas que visem à conscientização do agricultor sobre os benefícios associados à redução do uso de agrotóxicos.

${ }^{6}$ De acordo com os últimos resultados apresentados pelo Programa de Análise de Resíduos de Agrotóxicos nos Alimentos (PARA), detectaram-se resíduos de agrotóxicos em 51,89\% das 4.616 amostras analisadas (Agência Nacional de Vigilância Sanitária, 2019). 
De maneira geral, os resultados sugerem políticas voltadas para a ampliação da assistência técnica nas propriedades rurais para que a intensidade do uso de agrotóxicos seja reduzida. Visitas periódicas de técnicos e extensionistas para orientar corretamente quanto ao uso de pesticidas e incentivar a adoção do MIP e/ou MID podem beneficiar o desenvolvimento sustentável do setor agrícola brasileiro. É importante dizer que a regulação do setor em busca de disponibilizar produtos mais eficientes e menos nocivos à saúde e ao meio ambiente deve acompanhar tais políticas.

Ressalta-se que uma das dificuldades de estimar o impacto do uso de agrotóxicos é a limitação em relação à disponibilidade de dados. Informações referentes ao consumo de agrotóxicos e dados relacionados ao mercado desse insumo são de suma importância para que estudos complementares sejam realizados. A disponibilização de dados completos e desagregados são essenciais para pesquisas científicas.

\section{Referências}

Abadi, B. (2018). The determinants of cucumber farmers' pesticide use behavior in central Iran: Implications for the pesticide use management. Journal of Cleaner Production, 205, 1069-1081. http://dx.doi.org/10.1016/j.jclepro.2018.09.147

Agência Nacional de Vigilância Sanitária - ANVISA. Programa de Análise de Resíduos de Agrotóxicos em Alimentos - PARA. (2019). Relatório das amostras analisadas no período de 2017-2018. Recuperado em 30 de abril de 2021, de http://portal.anvisa.gov.br/documents/111215/0/ Relat\%C3\%B3rio+\%E2\%80\%93+PARA+20 17-2018_Final.pdf/e1d0c988-1e69-4054-9a3170355109 acc9

Alencar, G. V., Mendonça, E. S., Oliveira, T. S., Jucksch, I., \& Cecon, P. R. (2013). Percepção ambiental e uso do solo por agricultores de sistemas orgânicos e convencionais na Chapada da Ibiapaba, Ceará. Revista de Economia e Sociologia Rural, 51(2), 217-236. http://dx.doi. org/10.1590/S0103-20032013000200001

Atreya, K. (2008). Probabilistic assessment of acute health symptoms related to pesticide use under intensified Nepalese agriculture. International Journal of Environmental Health Research, 18(3), 187-208.

Bagheri, A., Bondori, A., Allahyari, M. S., \& Damalas, C. A. (2019). Modeling farmers' intention to use pesticides: an expanded version of the theory of planned behavior. Journal of Environmental Management, 248, 109291. http://dx.doi.org/10.1016/j.jenvman.2019.109291

Bia, M., \& Mattei, A. (2007). Application of the generalized propensity score: evaluation of public contributions to Piedmont enterprises (92 p.). Department of Public Policy and Public Choice - POLIS, The University of Piedmont Orientale.

Bia, M., \& Mattei, A. (2008). A Stata package for the estimation of the dose-response function through adjustment for the generalized propensity score. The Stata Journal, 8(3), 354-373. http://dx.doi.org/10.1177/1536867X0800800303

Brasil. (2012). Decreto n. 7.794, de 20 de agosto de 2012. Institui a Política Nacional de Agroecologia e Produção Orgânica. Recuperado em 25 de abril de 2021, de http://www. planalto.gov.br/ccivil_03/_ato2011-2014/2012/decreto/d7794.htm

Brasil. Ministério da Agricultura, Pecuária e Abastecimento - MAPA. (2019). Informações técnicas: registros concedidos 2005-2019. Recuperado em 30 de março de 2020, de https://www. gov.br/agricultura/pt-br/assuntos/insumos-agropecuarios/insumos-agricolas/agrotoxicos/ informacoes-tecnicas 
Brasil. Departamento de Informática do SUS - DATASUS. (2020). Intoxicação por agrotóxicos - Notificações registradas no Sistema de Informação de Agravos de Notificação - SINAN 2001 a 2006. Recuperado em 12 de janeiro de 2020, de http://tabnet.datasus.gov.br/cgi/ deftohtm.exe?sinanwin/cnv/agrobr.def

Bürger, J., Mol, F., \& Gerowitt, B. (2012). Influence of cropping system factors on pesticide use intensity: a multivariate analysis of on-farm data in North East Germany. European Journal of Agronomy, 40, 54-63. http://dx.doi.org/10.1016/j.eja.2012.02.008

Caliendo, M., \& Kopeinig, S. (2008). Some practical guidance for the implementation of propensity score matching. Journal of Economic Surveys, 22(1), 31-72. http://dx.doi.org/10.1111/j.14676419.2007.00527.x

Carneiro, F. F., Rigotto, R. M., Augusto, L. G. S., Friedrich, K., \& Búrigo, A. C. (Eds.). (2015). Dossiê Abrasco: um alerta sobre os impactos dos agrotóxicos na saúde. Rio de Janeiro: EPSJV; São Paulo: Expessão Popular.

Chandrasekara, A. I., Wettasinghe, A., \& Amarasiri, S. L. (1985). Pesticide usage by vegetable farmers. In Annual Research Conference ISTI. Gannoruwa, Sri Lanka.

Conte, O., Oliveira, F. T., Harger, N., Corrêa-Ferreira, B. S., Roggia, S., Prando, A. M., Possamai, E. J., Reis, E. A., \& Marx, E. F. (2019). Resultados do manejo integrado de pragas da soja na safra 2018/19 no Paraná. Londrina: Embrapa Soja.

Cunha, W. A. C., Freitas, A. F., \& Salgado, R. J. S. F. (2017). Efeitos dos programas governamentais de aquisição de alimentos para a agricultura familiar em Espera Feliz - MG. Revista de Economia e Sociologia Rural, 55(3), 427-444. http://dx.doi.org/10.1590/1234-5678180694790550301

Dasgupta, S., Mamingi, N., \& Meisner, C. (2001). Pesticide use in Brazil in the era of agroindustrialization and globalization. Environment and Development Economics, 6(4), 459-482. http://dx.doi.org/10.1017/S1355770X01000262

Empresa Brasileira de Pesquisa Agropecuária - EMBRAPA. (2019). Brasil é líder mundial em tecnologias de controle biológico. Recuperado em 25 de abril de 2021, de https://www. embrapa.br/en/busca-de-noticias/-/noticia/46366490/brasil-e-lider-mundial-em-tecnologiasde-controle-biologico

García-García, C. R., Parrón, T., Requena, M., Alarcón, R., Tsatsakis, A. M., \& Hernández, A. F. (2016). Occupational pesticide exposure and adverse health effects at the clinical, hematological and biochemical level. Life Sciences, 145, 274-283. http://dx.doi.org/10.1016/j.lfs.2015.10.013

Ghimire, N., \& Woodward, R. T. (2013). Under- and over-use of pesticides: An international analysis. Ecological Economics, 89, 73-81. http://dx.doi.org/10.1016/j.ecolecon.2013.02.003

Hashemi, S. M., Rostami, R., Hashemi, M. K., \& Damalas, C. A. (2012). Pesticide use and risk perceptions among farmers in Southwest Iran. Human and Ecological Risk Assessment, 18(2), 456-470. http://dx.doi.org/10.1080/10807039.2012.652472

Hirano, K., \& Imbens, G. (2005). The propensity score with continuous treatments. In Applied Bayesian modeling and causal inference from incomplete-data perspectives. Nova lorque: Wiley.

Hoffmann, R., \& Ney, M. G. (2010). Estrutura fundiária e propriedade agrícola no Brasil, grandes regiões e unidades da federação. Brasília: Ministério do Desenvolvimento Agrário.

Hoppin, J. A., Valcin, M., Henneberger, P. K., Kullman, G. J., Umbach, D. M., London, S. J., Alavanja, M. C. R., \& Sandler, D. P. (2010). Pesticide use and chronic bronchitis among farmers in the 
agricultural health study. American Journal of Industrial Medicine, 50(12), 969-979. http:// dx.doi.org/10.1002/ajim.20523

Hou, L., Liu, P., Huang, J., \& Deng, X. (2020). The influence of risk preferences, knowledge, land consolidation, and landscape diversification on pesticide use. Agricultural Economics, 51(5), 759-776. http://dx.doi.org/10.1111/agec.12590

Hu, R., Huang, X., Huang, J., Li, Y., Zhang, C., Yin, Y., Chen, Z., Jin, Y., Cai, J., \& Cui, F. (2015). Longand short-term health effects of pesticide exposure: a cohort study from China. PLoS One, 1066), e0128766. http://dx.doi.org/10.1371/journal.pone.0128766

Imbens, G. (2000). The role of the propensity score in estimating dose-response functions. Biometrika, 87(3), 706-710. http://dx.doi.org/10.1093/biomet/87.3.706

Instituto Brasileiro de Geografia e Estatística - IBGE. (2006). Censo agropecuário de 2006. Recuperado em 12 de dezembro de 2019, de https://sidra.ibge.gov.br/pesquisa/censoagropecuario/censo-agropecuario-2006/segunda-apuracao

Instituto Nacional do Câncer - INCA. (2019). Agrotóxicos. Recuperado em 28 de maio de 2019, de https://www.inca.gov.br/exposicao-no-trabalho-e-no-ambiente/agrotoxicos

Jallow, M. F. A., Awadh, D. G., Albaho, M. S., Devi, V. Y., \& Thomas, B. M. (2017). Pesticide risk behaviors and factors influencing pesticide use among farmers in Kuwait. The Science of the Total Environment, 574, 490-498. http://dx.doi.org/10.1016/j.scitotenv.2016.09.085

Jin, S., Bluemling, B., \& Mol, A. P. J. (2015). Information, trust and pesticide overuse: Interactions between retailers and cotton farmers in China. NJAS Wageningen Journal of Life Sciences, 72-73, 23-32. http://dx.doi.org/10.1016/j.njas.2014.10.003

Kim, K., Kabir, E., \& Jahan, S. A. (2017). Exposure to pesticides and the associated human health effects. The Science of the Total Environment, 575, 525-535. http://dx.doi.org/10.1016/j. scitotenv.2016.09.009

Li, Y., Palma, M. A., Hall, C. R., Khachatryan, H., \& Capps Junior, O. (2019). Measuring the effects of advertising on green industry sales: a generalized propensity score approach. Applied Economics, 51(12), 1303-1318. http://dx.doi.org/10.1080/00036846.2018.1527448

Lima, A. F. R., Ribeiro, F. G., \& Teixeira, G. D. S. (2020). Job qualification programs for Young apprentices: an analysis in the Brazilian Midwest. Education + Training, 62(6), 677-692. http://dx.doi.org/10.1108/ET-08-2019-0182

Mancini, F., Van Bruggen, A. H. C., Jiggins, J. L. S., Ambatipudi, A. C., \& Murphy, H. (2005). Acute pesticide poisoning among female and male cotton growers in India. International Journal of Occupational and Environmental Health, 11, 221-232.

Mariyono, J., Kuntariningsih, A., \& Kompas, T. (2018). Pesticide use in Indonesian vegetable farming and its determinants. Management of Environmental Quality, 29(2), 305-323. http:// dx.doi.org/10.1108/MEQ-12-2016-0088

Mello, C. M., \& Silva, L. F. (2013). Fatores associados à intoxicação por agrotóxicos: estudo transversal com trabalhadores da cafeicultura no sul de Minas Gerais. Epidemiologia e Serviços de Saúde: Revista do Sistema Unico de Saúde do Brasil, 22(4), 609-620. http:// dx.doi.org/10.5123/S1679-49742013000400007

Moreira, J. C., Jacob, S. C., Peres, F., Lima, J. S., Meyer, A., Oliveira-Silva, J. J., Sarcinelli, P. N., Batista, D. F., Egler, M., Faria, M. V. C., Araújo, A. J., Kubota, A. H., Soares, M. O., Alves, S. R., Moura, C. M., \& Curi, R. (2002). Avaliação integrada do impacto do uso de agrotóxicos 
sobre a saúde humana em uma comunidade agrícola de Nova Friburgo, RJ. Ciência \& Saúde Coletiva, 7(2), 299-311. http://dx.doi.org/10.1590/S1413-81232002000200010

Neghab, M., Momenbella-Fard, M., Naziaghdam, R., Salahshour, N., Kazemi, M., \& Alipour, H. (2014). The effects of exposure to pesticides on the fecundity status of farm workers resident in a rural region of Fars province, southern Iran. Asian Pacific Journal of Tropical Biomedicine, 4(4), 324-328. http://dx.doi.org/10.12980/APJTB.4.2014C586

Neves, P. D. M., \& Bellini, M. (2013). Intoxicações por agrotóxicos na mesorregião norte central paranaense, Brasil - 2002 a 2011. Ciência \& Saúde Coletiva, 18(11), 3147-3156. http://dx.doi. org/10.1590/S1413-81232013001100005

Neves, P. D., Mendonça, M. R., Bellini, M., \& Pôssas, I. B. (2020). Intoxicação por agrotóxicos agrícolas no estado de Goiás, Brasil, de 2005-2015: análise dos registros nos sistemas de informação. Ciência \& Saúde Coletiva, 25(7), 2743-2754. http://dx.doi.org/10.1590/141381232020257.09562018

Oerke, E. C., \& Dehne, H. W. (2004). Safeguarding production-losses in major crops and the role of crop protection. Crop Protection, 23(4), 275-285. http://dx.doi.org/10.1016/j. cropro.2003.10.001

Oliveira, G. R., Menezes, R. T., \& Resende, G. M. (2018). Efeito dose resposta do fundo constitucional de financiamento do Centro-Oeste (FCO) no estado de Goiás. Nova Economia, 28(3), 9651000. http://dx.doi.org/10.1590/0103-6351/3397

Oliveira, N. P., Moi, G. P., Atanaka-Santos, M., Silva, A. M. C., \& Pignati, W. A. (2014). Malformações congênitas em municípios de grande utilização de agrotóxicos em Mato Grosso, Brasil. Ciência \& Saúde Coletiva, 19(10), 4123-4130. http://dx.doi.org/10.1590/1413-812320141910.08512014

Papa, G., Yamamoto, P. T., Garcia, J. F., Botton, M., \& Kagi, F. Y. (2014). Manejo de resistência de pragas a agrotóxicos. Recuperado em 28 de julho de 2020, de https://www.embrapa.br/en/ busca-de-publicacoes/-/publicacao/1004874/manejo-de-resistencia-de-pragas-a-agrotoxicos

Parra, J. R. P. (2014). Biological control in Brazil: an overview. Scientia Agrícola, 71(5), 345-355. http://dx.doi.org/10.1590/0103-9016-2014-0167

Pignati, W. A., Lima, F. A. N. S., Lara, S. S., Correa, M. L. M., Barbosa, J. R., Leão, L. H. C., \& Pignatti, M. G. (2017). Distribuição espacial do uso de agrotóxicos no Brasil: uma ferramenta para a Vigilância em Saúde. Ciência \& Saúde Coletiva, 22(10), 3281-3293. http://dx.doi. org/10.1590/1413-812320172210.17742017

Pignati, W., Oliveira, N. P., \& Silva, A. M. C. (2014). Vigilância aos agrotóxicos: quantificação do uso e previsão de impactos na saúde-trabalho-ambiente para os municípios brasileiros. Ciência \& Saúde Coletiva, 19(12), 4669-4678. http://dx.doi.org/10.1590/1413-812320141912.12762014

Porto, M. F., \& Soares, W. L. (2012). Modelo de desenvolvimento, agrotóxicos e saúde: um panorama da realidade agrícola brasileira e propostas para uma agenda de pesquisa inovadora. Revista Brasileira de Saúde Ocupacional, 37(125), 17-31. http://dx.doi.org/10.1590/ S0303-76572012000100004

Rahman, S. (2003). Farm-level pesticide use in Bangladesh: determinants and awareness. Agriculture, Ecosystems \& Environment, 95(1), 241-252. http://dx.doi.org/10.1016/S01678809(02)00089-0

Rahman, S. (2015). Agroecological, climatic, land elevation and socio-economic determinants of pesticide use at the farm level in Bangladesh. Agriculture, Ecosystems \& Environment, 212, 187-197. http://dx.doi.org/10.1016/j.agee.2015.07.002 
Rahman, S., \& Chima, C. D. (2018). Determinants of Pesticide Use in Food Crop Production in Southeastern Nigeria. Agriculture, 8(3), 35. http://dx.doi.org/10.3390/agriculture8030035

Regidor, E., Ronda, E., García, A. M., \& Domínguez, V. (2004). Paternal exposure to agricultural pesticides and cause specific fetal death. Occupational and Environmental Medicine, 61(4), 334-339. http://dx.doi.org/10.1136/oem.2003.009043

Rosenbaum, P. R., \& Rubin, D. B. (1983). The central role of the propensity score in observational studies for causal effects. Biometrika, 70(1), 41-55. http://dx.doi.org/10.1093/biomet/70.1.41

Sambuichi, R. H. R., Moura, I. F., Mattos, L. M., Ávila, M. L., Spínola, P. A. C., \& Silva, A. P. M. (2017). A política nacional de agroecologia e produção orgânica no Brasil: uma trajetória de luta pelo desenvolvimento rural sustentável. Brasília: IPEA.

Sankoh, A. I., Whittle, R., Semple, K. T., Jones, K. C., \& Sweetman, A. J. (2016). An assessment of the impacts of pesticide use on the environment and health of rice farmers in Sierra Leone. Environment International, 94, 458-466. http://dx.doi.org/10.1016/j.envint.2016.05.034

Sheahan, M., \& Barrett, C. (2017). Ten striking facts about agricultural input use in Sub-Saharan Africa. Food Policy, 67, 12-25. http://dx.doi.org/10.1016/j.foodpol.2016.09.010

Sheahan, M., Barrett, C. B., \& Goldvale, C. (2017). Human health and pesticide use in SubSaharan Africa. Agricultural Economics, 48(S1), 27-41. http://dx.doi.org/10.1111/agec.12384

Soares, W. L., \& Porto, M. F. S. (2009). Estimating the social cost of pesticide use: an assessment from acute poisoning in Brazil. Ecological Economics, 68(10), 2721-2728. http://dx.doi. org/10.1016/j.ecolecon.2009.05.008

Soares, W. L., \& Porto, M. F. S. (2012). Uso de agrotóxicos e impactos econômicos sobre a saúde. Revista de Saude Publica, 46(2), 209-217. http://dx.doi.org/10.1590/S0034-89102012005000006

Soares, W. L., Freitas, E. A. V., \& Coutinho, J. A. (2005). Trabalho rural e saúde: intoxicações por agrotóxicos no município de Teresópolis - RJ. Revista de Economia e Sociologia Rural, 43(4), 685-701. http://dx.doi.org/10.1590/S0103-20032005000400004

Staback, D., Blanck, P. L., Mariussi, V., \& Galante, V. A. (2020). Uso do MIP como estratégia de redução de custos na produção de soja no estado do Paraná. Revista Americana de Empreendedorismo e Inovação, 2(1), 187-200.

Ueker, M. E., Silva, V. M., Moi, G. P., Pignati, W. A., Mattos, I. E., \& Silva, A. M. C. (2016). Parenteral exposure to pesticides and occurence of congenital malformations: hospital-based casecontrol study. BMC Pediatrics, 16(1), 125. http://dx.doi.org/10.1186/s12887-016-0667-x

Valadares, A., Alves, F., \& Galiza, M. (2020). O crescimento do uso de agrotóxicos: uma análise descritiva dos resultados do Censo Agropecuário 2017. Recuperado em 4 de janeiro de 2021, de https://www.ipea.gov.br/portal/index.php?option=com_content\&view=article\&id=35512

Zhang, L., Li, X., Yu, J., \& Yao, X. (2018). Toward cleaner production: What drives farmers to adopt eco-friendly agricultural production? Journal of Cleaner Production, 184, 550-558. http:// dx.doi.org/10.1016/j.jclepro.2018.02.272 